\title{
An Empirical Note on Factor Shares HERNANDO ZULETA
}

Universidad del Rosario, Bogotá, Colombia.

e-mail: hernando.zuleta84@urosario.edu.co

Telephone: 57 (1) 2970200.

Address: Casa Pedro Fermín, Calle 14 \# 4 - 69, Bogotá Colombia.

\begin{abstract}
In this study, we propose an explanation for why labor and capital shares do not seem to have a trend: an increasing trend in physical capital share is compensated by a decreasing trend in land share. Similarly, an increasing trend in human capital share is compensated by a decreasing trend in raw labor share. We also find empirical support for the claim that the elasticity of output with respect to reproducible factors, human and physical capital, is positively correlated with the income level. This result has important implications for economic growth theory and for empirical exercises related to economic growth.
\end{abstract}

JEL classification: E1, F0, O0.

Keywords: Factor Income Shares, Biased Innovations, Elasticity of output with respect to factors.

\section{Introduction}

In general, the existing literature of empirical economic growth ignores the fact that land is a factor of production (Barro and Sala-i-Martin, 1992; Mankiw, Romer and Weil, 1992; and Durlauf and Johnson, 1995). In this note we show that land has a positive significant effect on total output. We also show that the idea that labor income share does not decrease or increase with time or with the stage of development does not imply that the elasticity of output with respect to these factors be constant. Indeed, the standard measures of labor income share include raw labor and human capital income shares. ${ }^{1}$ In the same way, the standard measure of capital income share includes land income share. Therefore, it is possible that an increasing trend in physical capital income share is compensated by a decreasing trend in land income share. Similarly, an increasing trend in human capital income share may be compensated by a decreasing trend in raw labor income share. ${ }^{2}$

1 Cobb and Douglas (1928); Kaldor (1961) and Gollin (2002) among others

${ }^{2}$ For an alternative explanation, see Zuleta (2007a) 
There exists evidence suggesting that the share of reproducible factors is positively correlated with income per worker: In a panel data Mincerian regression, Krueger (1999) estimates raw labor shares for the United States. According to his results the share of raw labor has decreased for the past fifty years. Similarly, in a cross section study Caselli and Feyrer (2007) show that the share of physical capital is positively correlated with income per worker. However, good share data for large samples are not available. Given this restriction, we use a simplified model of factor saving innovations in order to relate unobserved factor shares to the observed data on factors and income. We then estimate the resulting equations for OECD countries during the period 1965-2000 and use the results to construct estimates of factor shares. Finally, we compare the estimated values of factor shares with the levels of GDP per worker.

Our results suggest a positive correlation between the share of reproducible factors (human and physical capital) and the relative abundance of the factors (and income per capita). This result contrasts with Gollin's assertion that there is no systematic relation between shares and income levels (see Gollin, 2002). We claim that such a relation exists, but to see it one has to distinguish between reproducible and non-reproducible factors.

This insight has important implications for economic growth theory and for empirical exercises related to economic growth. First, theoretical growth models should be able to predict a positive relation between factor shares and relative factor abundance. In particular, growth models should include the possibility of biased innovations. ${ }^{3}$ Second, growth accounting exercises and growth regressions should include more than two factors. Third, empirical exercises both at the aggregate and at the industry level should take into account that factor shares are not constant.

The rest of this paper is organized as follows. In Section II we motivate the inclusion of land as a factor of production. In section III, we present three theoretical reasons why the elasticity of output with respect to reproducible factors should be positively correlated with the stage of development. In section IV, we present a model of factor saving innovations and derive the elasticity of output with respect to reproducible factors. In section $\mathrm{V}$, we run a growth

\footnotetext{
3 Theoretical models of this type has been presented by Kennedy (1964), Zeira (1998), Acemoglu (2002), Zuleta (2006) and Peretto and Seater (2006) among others.
} 
regression taking into account the fact that factor shares depend on factor abundance. Section VI concludes.

\section{Land is a factor of production}

Traditionally, models of economic growth have not included land as a factor of production. Seminal works like Solow (1956) consider two factors of production, capital and labor. After the new growth theory, models have included also human capital (Lucas, 1989 and Romer, 1990). However, land is essential for the production of several goods and it is relatively easy to see that the land income share is positive.

In order to get the factor shares scholars observe total output and labor income from national accounts and compute the ratio. Once the labor share is calculated, the capital share is obtained residually. Recently the World Bank followed the same approach to obtain the share of land. The measure of rents is based on the value of output from that form of capital in a given year. ${ }^{4}$

With regard to the theory of economic growth the works by Hansen and Prescott (2002) and Caselli and Feyrer (2007) present theories where land is explicitly modeled as a factor of production.

Hansen and Prescott (2002) explain that the transition from a Malthusian economy to a Solowtype economy implies that land has become less important as a factor of production. Indeed, the value of farmland relative to the value of gross national product (GNP) has declined dramatically in past two centuries. ${ }^{5}$

\footnotetext{
${ }^{4}$ For subsoil resources, the World Bank estimates the future growth of rents and a time horizon to depletion. For forest products, rents are estimated as the value of timber produced (at local market prices where possible) minus an estimate of the cost of production. Adjustments are made for sustainability based on the volume of production and total amount of usable timberland. The rents to other forest resources are estimated as fixed value per acre for all non-timber forest. Rents from cropland are estimated as the value of agricultural output minus production costs. ${ }^{5}$ Table 2 in Hansen and Prescott reports this ratio for the U.S. since 1870, the first year the needed census data are available. The value of farmland relative to annual GNP has fallen from 88 percent in 1870 to less than 5 percent in 1990.
} 
Using the data compiled by the World Bank, Caselli and Feyrer (2007) separate natural capital from reproducible capital and calculate the share of output paid to reproducible capital. The latter, is our object of interest. This differential treatment of natural and reproducible capital implies that standard measures of the capital share (obtained as 1 minus the labor share) are not appropriate because these measures include both the income flowing to reproducible capital and the rents of natural capital. An interesting implication of Caselli and Feyrer (2007) is that land, as a factor of production, is more important in poor countries.

\section{Factor shares and development}

The empirical literature on economic growth treats the elasticity of output with respect to capital (and labor) as constant and equal to the income share of capital (labor) (see Solow, 1957; Young, 1994 or Easterly and Levine, 2002 among others). However, according to different economic growth models of biased innovations factor scarcity generates incentives to invest in factor saving innovations, that is, people invest to reduce the need of scarce factors and increase the relative use of abundant factors. Then, the elasticity of output with respect to nonreproducible factors decreases with the stage of development (see Zuleta, 2006 and Peretto and Seater, 2006).

There are two additional reasons why the elasticity of output with respect to reproducible factors should be positively correlated with the stage of development: (i) The Hecksher-Ohlin theory predicts that countries specialize and export those goods that make intensive use of locally abundant factors, while importing (producing less) goods that make intensive use of factors that are locally scarce (Hecksher, 1919 and Ohlin,1939). Therefore, specialization should increase the elasticity of aggregate output with respect to abundant factors. (ii) Location-specific advantages can help explain the nature and direction of FDI (see Dunning, 1988). Therefore, firms producing labor-intensive goods are likely to invest in labor abundant countries, while firms producing capital-intensive goods are likely to invest in capital abundant countries. This implies that the behavior of FDI, generates expansion in the sectors that use intensively abundant factors and, as a result, should increase the elasticity of aggregate output with respect to abundant factors. 
This apparent contradiction may respond to the fact that the standard measures of labor income includes raw labor and human capital income and, in the same way, the standard measure of capital income includes land income. Therefore, it is possible that an increasing trend in physical capital income share is compensated by a decreasing trend in land income share. Similarly, an increasing trend in human capital income share may be compensated by a decreasing trend in raw labor income share.

In the next section, we briefly present a model of factor saving innovations and derive the elasticity of output with respect to reproducible factors. In section $\mathrm{V}$ we use these results to run a growth regression considering endogenous facto shares.

\section{Modeling technological change}

We assume that for any technology there is a Cobb-Douglas production function and technologies are differentiated by their capital intensity, $\alpha$, with the restriction that $\alpha \epsilon[0,1)$. Hence, for every technology labor is a necessary input. Any technological change has a nonnegative cost which depends on the desired $\alpha$. This cost is paid by the capital owners before the production process begins. So, when firms want to improve technologies, a share of the assets must be devoted to change the technology $\alpha$.

Following Zuleta (2007b), we assume that for $B$ units of output devoted to build capital goods operating with technology $\alpha^{\prime}$, the number of capital goods is given by $K=B\left(1+\left[\ln \left(\eta-\alpha^{\prime}\right)-\ln (\eta-\alpha)\right]\right) \quad$ where $\quad \alpha^{\prime}$ is the new technology, $\alpha$ is the existing technology and $\eta$ is a parameter that indicates the cost of changing the technology. The parameter $\eta$ is assumed to be smaller than one, $\eta \leq 1$, otherwise $\alpha^{\prime}$ can be bigger than 1 .

$B$ can be thought as the amount of assets devoted to build capital K and technology $\alpha^{\prime}$. The depreciation rate is assumed to be $100 \%$ so that today's capital is equal to today's capital investment, which in turn equals B minus what is spent on carrying out technical change.

Therefore, the output produced by a firm using $K$ units of capital and technology $\alpha^{\prime}$ is given by $A\left(B\left(1+\left(\ln \left(\eta-\alpha^{\prime}\right)-\ln (\eta-\alpha)\right)\right)\right)^{\alpha} L^{1-\alpha}$ where $L$ is labor. 
Firm owners decide the technology they want to use given the amount of assets. The capital intensity of the technology is modified only if the gain derived from the change is positive. If assets are only devoted to increase the stock of capital, the production per unit of labor is given by $A\left(\frac{B}{L}\right)^{\alpha}$.

For tractability, we assume that only one technology is used at a time. We are aware of the fact that all values of $\alpha$ below the current value are known and firms have incentives to use labor intensive technologies. ${ }^{6}$ However, the qualitative prediction regarding the equilibrium relation between reproducible factors and factor shares does not depend on such simplifying assumption.

Given the factor prices, firms choose factors in order to maximize profits. Given the amount of assets, firms choose technology to maximize income,

$$
\max _{\alpha^{\prime}} A\left(B\left(1+\ln \left(\eta-\alpha^{\prime}\right)-\ln (\eta-\alpha)\right)\right)^{\alpha^{\prime}} L^{1-\alpha^{\prime}} \text { s.t. } \quad \alpha^{\prime} \geq 0
$$

Thus, the optimal level of $\alpha^{\prime}$ is given by the First Order Condition:

$$
A K^{\alpha^{\prime}} L^{1-\alpha^{\prime}}\left(\log (k)-\frac{\alpha^{\prime}}{\eta-\alpha^{\prime}} \frac{B}{K}\right)+\lambda_{\alpha}=0
$$

Therefore, in the interior solution $\lambda_{\alpha}=0$ and $\alpha^{\prime}=\max \left\{0, \eta \frac{\frac{K}{B} \log k}{1+\frac{K}{B} \log k}\right\}$

Note that $\frac{K}{B}=\frac{1}{1+\ln \left(\eta-\alpha^{\prime}\right)-\ln (\eta-\alpha)}$, so when the technology is constant $\frac{K}{B}=1$.

\footnotetext{
${ }^{6}$ Zuleta (2006) and Peretto and Seater (2006) found this result in more elaborated models of factor saving innovations.
} 
For purposes of estimation we assume that the set of technologies is discrete and that technology remains constant for periods of 5 years. Therefore, within periods the capital share is given by,

$$
\alpha^{\prime}=\eta \frac{\log k}{1+\log k}
$$

Finally, this result can be easily extended to a production function with more than two factors (see Zuleta, 2007b), in such a way that

$$
\alpha^{\prime}=\eta \frac{\log k}{1+\log k} \text { and } \beta^{\prime}=\lambda \frac{\log h}{1+\log h}
$$

Equation 2 implies that the share of each factor positively depends on its relative abundance.

\section{Factor shares and economic growth}

In this section we estimate growth regressions using panel data. We use the data of De la Fuente and Domenech ${ }^{7}$ (2001) from OECD countries for GDP, physical capital and human capital. For the variables land (T) and raw labor (L) we use data from the World Development Indicators (2002).

Consider an aggregate production function, which combines two reproducible factors, human and physical capital ( $\mathrm{H}$ and $\mathrm{K}$ ) and two non reproducible factors, land and raw labor ( $\mathrm{T}$ and $\mathrm{L}$ ) in a Cobb-Douglas:

(3) $Y=A K^{\alpha} H^{\beta} T^{\gamma} L^{1-\alpha-\beta-\gamma}$.

\footnotetext{
${ }^{7}$ Countries: Australia, Austria, Belgium, Canada, Denmark, Finland, France, Germany, Greece, Ireland, Italy, Japan, Netherlands, New Zealand, Norway, Portugal, Spain, Sweden, Switzerland, USA, UK. Years: 1960, 1965, 1970, 1975, 1980, 1985, 1990, 1995.
} 
Therefore, income per capital is $Y=A k^{\alpha} h^{\beta} t^{\gamma}$, where $k$ is capital per worker, $h$ is human capital per worker and $t$ is land per worker. ${ }^{8}$ By taking logarithms and differences:

(4) $\frac{\Delta y}{y}=\frac{\Delta A}{A}+\alpha \frac{\Delta k}{k}+\beta \frac{\Delta h}{h}+\gamma \frac{\Delta t}{t}$

Using the results of section $\mathrm{V}$ we introduce endogenous elasticity of output with respect to factors. If the elasticity of output with respect to factors is equal to the factors income share and total labor income share is constant then the changes in $\beta$ and $\alpha$ must be reflected in reductions of $1-\alpha-\beta-\gamma$ and $\gamma$. In other words $\gamma$ must be a variable and not a parameter.

We consider three different specifications for $\gamma$ that can be consistent with this relation:

1. $\gamma=\rho(1-\alpha)$, where $\rho$ is a parameter to be estimated. If $\rho>0$ the share of physical capital grows as the share of land decreases.

2. $\gamma=\mu-\alpha$, where $\mu$ is a parameter to be estimated. In this case, the share of non-human factors is constant $(\mu)$.

3. $\gamma=\psi \frac{\log t}{1+\log t}$. In this case the elasticity of output with respect to land depends on the relative abundance of land (compared with raw labor).

In specifications 1 and 2 we assume that any increase in the share of physical capital is reflected in a decrease in the share of land. In specification 1 an increase of one unit in $\alpha$ is reflected in a decrease of $\rho$ units in $\gamma$, while in specification 2 an increase of one unit in $\alpha$ is reflected in a decrease of one unit in $\gamma$.

In specification 3 we implicitly assume that the share of land can be changed in the same way in which the share of reproducible factors is changed. The functional form assumed in

\footnotetext{
${ }^{8}$ The variable $t$ is squared kilometers per 10 workers.
} 
specification 3 is equivalent to equation $2\left(\alpha^{\prime}=\eta \frac{\log k}{1+\log k}\right)$. In other words, we are defining the relative abundance of any factor $J$ as the ratio $\frac{J}{L}$.

We assume that the elasticity of output with respect to different factors can vary in time and thus may have different values at the beginning of each sub-period. However, since we are considering periods of five years we assume that the elasticities are constant within periods. Therefore, the growth rate of income per capita is given by:

(5) $\frac{\Delta y_{i}}{y_{i}}=\frac{\Delta A_{i}}{A_{i}}+\left(\eta \frac{\log k_{i, 0}}{1+\log k_{i, 0}}\right) \frac{\Delta k_{i}}{k_{i}}+\left(\lambda \frac{\log h_{i, 0}}{1+\log h_{i, 0}}\right) \frac{\Delta h_{i}}{h_{i}}+\gamma_{0, i} \frac{\Delta t_{i}}{t_{i}}$

In order to control for technological convergence, we follow De la Fuente and Domenech (2001). For each country $i$, at any time, TFP is obtained as ${ }^{9}$

$$
A_{i}=\frac{y_{i}}{k_{i}^{\alpha} h_{i}^{\beta} t_{i}^{\gamma}}
$$

Therefore, if there is technological convergence, then

(7) $\frac{\Delta A_{i}}{A_{i}}=\mu+\delta\left(\log y_{0, i}-\left(\eta \frac{\log k_{i, 0}}{1+\log k_{i, 0}}\right) \log k_{0, i}-\left(\lambda \frac{\log h_{i, 0}}{1+\log h_{i, 0}}\right) \log h_{0, i}-\gamma_{0, i} \log t_{0, i}\right)+\varepsilon_{i}+\tau_{t}+\eta$

where the parameter $\delta$ indicates the speed of technological convergence, $\mu, \tau$ and $\varepsilon$ are changes in technology that are not explained by technological convergence, $\mu$ is common to all countries and constant, $\tau_{\mathrm{t}}$ is common to all countries but changes in time, $\varepsilon$ is country specific and it is captured by country dummies and $\eta$ is the error term.

\footnotetext{
${ }^{9}$ In growth regressions technological convergence is a common result and some authors claim that in order to estimate adequately factor share you need to control for technological convergence (see De la Fuente and Domenech, 2001).
} 
Combining equations 5 and 7, we estimate the growth regressions. The results are presented in table 1 (standard errors in parenthesis.) The coefficients $\eta$ and $\lambda$ are positive and significantly different from zero in all cases. The coefficients $\rho, \mu$ and $\psi$ are also positive and significantly different from zero. This evidence supports the idea that the contribution of physical and human capital accumulation to economic growth is higher in capital abundant economies.

We also use the data and the estimated parameters to calculate the values of $\alpha, \beta$ and $\gamma$ for all the countries in different years. These numbers are similar to the predicted by conventional wisdom. However, two results call the attention: (i) In specification 2, the elasticity of output with respect to land appears to be negative $(\gamma<0)$ for some observations, suggesting that this specification is not adequate. In specification 1 and 3 the results are consistent with the conventional wisdom, that is, the share of human factors is between 0.70 and 0.75 and the share of every factor is positive.

In figure 1 we plot estimated factors shares of reproducible factors against the logarithm of GDP per worker using specification 1. Again, according to our results there exists a positive correlation between the elasticity of output with respect to reproducible factors and the level of output per worker. Finally, in figure 2 we plot the estimated share of human factors, i.e., raw labor and human capital, and the estimated share on non-human factors against GDP per worker. The estimated share of non-human factors is close to 0.3 in all cases (see figure 2) and, even though there exists a correlation between human shares and GDP per worker, the variation in factor shares is very small.

Note that the estimated value of $\eta$ is about 0,34 . This result implies that the elasticity of output with respect to physical capital is always smaller than one, so given the amount of human capital, the marginal productivity of capital converges to zero as the stock of physical capital goes to infinity. In other words, without human capital accumulation long run growth is not possible.

Note also that the estimated value of $\eta+\lambda$ is about 1,2 . Therefore, the elasticity of output with respect to reproducible factors does not converge to zero as the amount of assets goes to infinity 
(Inada conditions do not hold). In other words, the estimated values of $\eta$ and $\lambda$ suggest that long run growth is possible.

[Insert Figures 1 and 2]

\section{Conclusions}

Theories of international trade, FDI and factor saving innovations provide three different theoretical reasons why the elasticity of output with respect to reproducible factors, namely, physical capital and human capital, should be positively correlated with the stage of development. If factor prices are determined by factor marginal productivities then the elasticity of output with respect to factors determines factor income shares. This implies that there are three different theoretical reasons why the income share of reproducible factors should be positively correlated with the stage of development.

We argue that the existence of more than one reproducible factor and more than one nonreproducible factor helps explain these facts. Indeed, an increasing trend in physical capital income share is partially compensated by a decreasing trend in land income share. Similarly, an increasing trend in human capital income share is partially compensated by a decreasing trend in raw labor income share.

We find positive correlation between the estimated shares of reproducible factors (human and physical capital) and the relative abundance of the factors (and income per capita). This result contrasts with the assertion that there is no systematic relation between shares and income levels (see Gollin, 2002).

Even though the share of human factors does not present any trend, the elasticity of output with respect to reproducible factors depends on the stage of development of the countries. This result has important implications for economic growth theory and for empirical exercises related to economic growth (accounting and econometrics). In particular, endogenous growth models should include the possibility of factor saving and factor using innovations and empirical 
exercises should consider the possibility of changes in the elasticity of output with respect to factors.

\section{Bibliography}

Acemoglu, D. (2002) 'Directed Technical Change' Review of Economic Studies, 69 (4) 781-809.

Barro, R. and Sala-i-martin, X. (1992) 'Convergence' Journal of Political Economy, 100 (2), 223-251.

Caselli, F. and Feyrer, J. (2007) 'The Marginal Product of Capital' The Quarterly Journal of Economics, 122(2), 535-568.

Cobb, C. and Douglas, P.H. (1928) 'A theory of Production'. American Economic Review, 18, 139-165.

De la Fuente A. and Domenech, R. (2001) 'Schooling Data, Technological Diffusion, and the

Neoclassical Model' American Economic Review, 91 (2), 323-27.

Dunning, J. H. (1998) Explaining International Production. London: Unwin Hyman.

Durlauf, S. and Johnson, P. (1995) 'Multiple Regimes and Cross-Country Growth Behavior' Journal of Applied Econometrics December, 10 (4), 365-384

Easterly, W. and Levine, R. (2001) 'It's Not Factor Accumulation: Stylized Facts and Growth

Models’ World Bank Economic Review, 15 (2), 177-219

Gollin, D. (2002) 'Getting Income Shares Right'. Journal of Political Economy, 110 (2), 458-474.

Hansen, Gary and Prescott, Edward. (2002) 'From Malthus to Solow', The American Economic Review, 92 (4), 1205-1217.

Heckscher, E. F. (1919) 'The Effect of Foreign Trade on the Distribution of Income' Ekonomisk Tidskrif, 497-512.

Kaldor, N. (1961) 'Capital Accumulation and Economic Growth' In FA Lutz and DC Hague (eds), The

Theory of Capital. New York St, Martin's Press, 177-222.

Kennedy, C. (1964) 'Induced Bias in Innovation and the Theory of Distribution' Economic Journal, LXXIV 1964, 541-547.

Krueger, A. (1999) 'Measuring Labor's Share'. American Economic Review, 89 (2), $45-51$.

Mankiw, G.; Romer, D. and Weil, D. (1992) 'A contribution to the Empirics of Economic Growth', Quarterly Journal of Economics, 107 (2), 407-437.

Ohlin, Bertil (1993) Interregional and International Trade. Cambridge: Harvard University Press.

Peretto, Pietro and Seater, John (2006) 'Augmentation or Elimination?', working paper

http://ideas.repec.org/p/deg/conpap/c011_060.html

Rhee, Changyong (1991) 'Dynamic Inefficiency in an Economy with Land' Review of Economic

Studies, 58 (4) 791-797. 
Solow, Robert (1956) 'A contribution to the Theory of Economic Growth'. Quarterly Journal of Economics, 70 february, 65-94.

Solow, R. (1957) 'Technical Change and the Aggregate Production Function'. Review of Economics and Statistics, 39, 312-320.

World Bank, Where is The Wealth of Nations? (The World Bank, 2006).

Young, A. (1995) 'The Tyranny of Numbers: Confronting the Statistical Realities of the East Asian

Growth Experience'. Quarterly Journal of Economics, 110: 641-680

Zeira, J. (1998) 'Workers, Machines and Economic Growth'. Quarterly Journal of Economics, 113 (4), 1091-1118.

Zuleta, H. (2006) 'Factor Saving Innovations and Factor Income Shares'. Working Paper, Universidad del Rosario. http://papers.ssrn.com/sol3/papers.cfm?abstract_id=967281

Zuleta, Hernando (2007a) 'Why Factor Shares Seem to be Constant' Journal of International Trade and Economic Development, Volume 16, Issue 4 January 2007, 551 - 557.

Zuleta, Hernando (2007b) 'Biased Technological Change, Human Capital and Factor Shares' Working Paper, Universidad del Rosario.

http://www2.urosario.edu.co/urweb/FASE1/economia/documentos/pdf/dt17.pdf 
Table 1

Endogenous elasticity of output with respect to land, physical capital and human capital Panel data estimation

\begin{tabular}{|c|c|c|c|}
\hline & $\gamma=\rho(1-\alpha)$ & $\gamma=\stackrel{2}{\mu-\alpha}$ & $\gamma=\psi \frac{\log t}{1+\log t}$ \\
\hline$\eta$ & $\begin{array}{l}0.340^{* * * *} \\
(0.014)\end{array}$ & $\begin{array}{l}0.344^{* * *} \\
(0.051)\end{array}$ & $\begin{array}{l}0.344^{* * *} \\
(0.014) \\
\end{array}$ \\
\hline$\lambda$ & $\begin{array}{l}0.869^{* * * *} \\
(0.296)\end{array}$ & $\begin{array}{l}1.152^{* * *} \\
(0.247)\end{array}$ & $\begin{array}{l}0.867^{* * * *} \\
(0.274)\end{array}$ \\
\hline$\delta$ & $\begin{array}{l}0.069^{* * * *} \\
(0.007)\end{array}$ & $\begin{array}{l}0.069^{* * * *} \\
(0.007)\end{array}$ & $\begin{array}{l}0.068^{* * * *} \\
(0.007)\end{array}$ \\
\hline Constant & $\begin{array}{l}0.145^{* * *} \\
(0.014)\end{array}$ & $\begin{array}{l}0.141^{* * *} \\
(0.014)\end{array}$ & $\begin{array}{l}0.144^{* * *} \\
(0.014)\end{array}$ \\
\hline$\rho$ & $\begin{array}{l}0.015^{*} \\
(0.006)\end{array}$ & & \\
\hline$\mu$ & & $\begin{array}{l}0.277^{* * *} \\
(0.039) \\
\end{array}$ & \\
\hline$\psi$ & & & $\begin{array}{l}0.0095^{*} \\
(0.005)\end{array}$ \\
\hline Observations & 123 & 123 & 123 \\
\hline Adj-R square & 0.77 & 0.77 & 0.77 \\
\hline \multicolumn{4}{|c|}{$\begin{array}{l}\text { Standard error in parentheses. } \\
* * * \text { Significant at } 1 \% \text { level; } * \text { Significant at } 5 \% \text { level; * Significant at } 10 \% \text { level } \\
\text { Country Dummies: Belgium, USA, Finland, France, Italy, Ireland, Netherlands, New } \\
\text { Zealand and Spain. } \\
\text { Multiplicative Dummies: Finland, Ireland and New Zealand for human capital. Ireland for } \\
\text { physical capital. } \\
\text { Time Dummies: } 1970,1975 \text {, and } 1980 .\end{array}$} \\
\hline
\end{tabular}




\section{Figure 1}

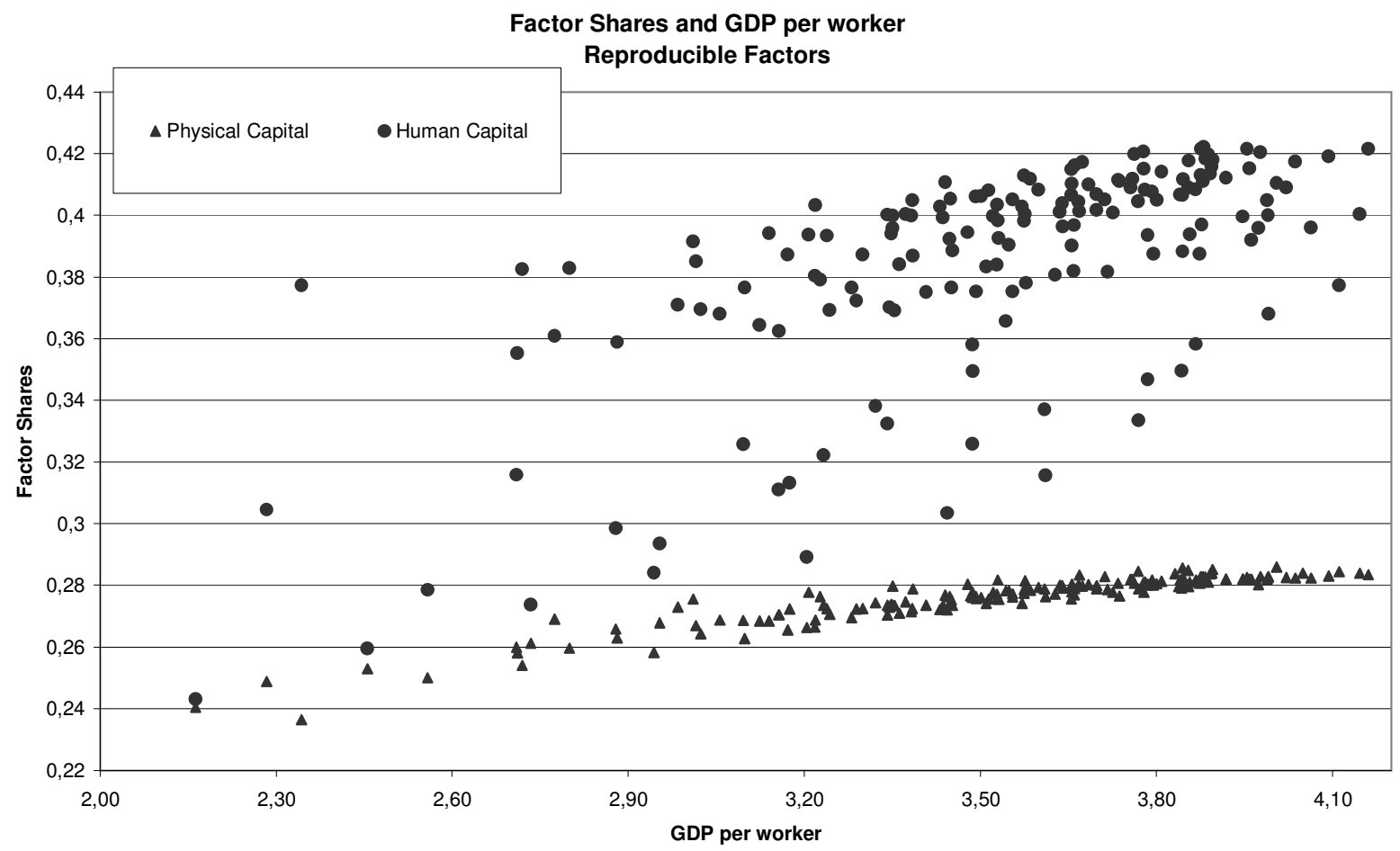

Figure 2

Factor Shares and GDP per worker

Humand and Non-human Factors

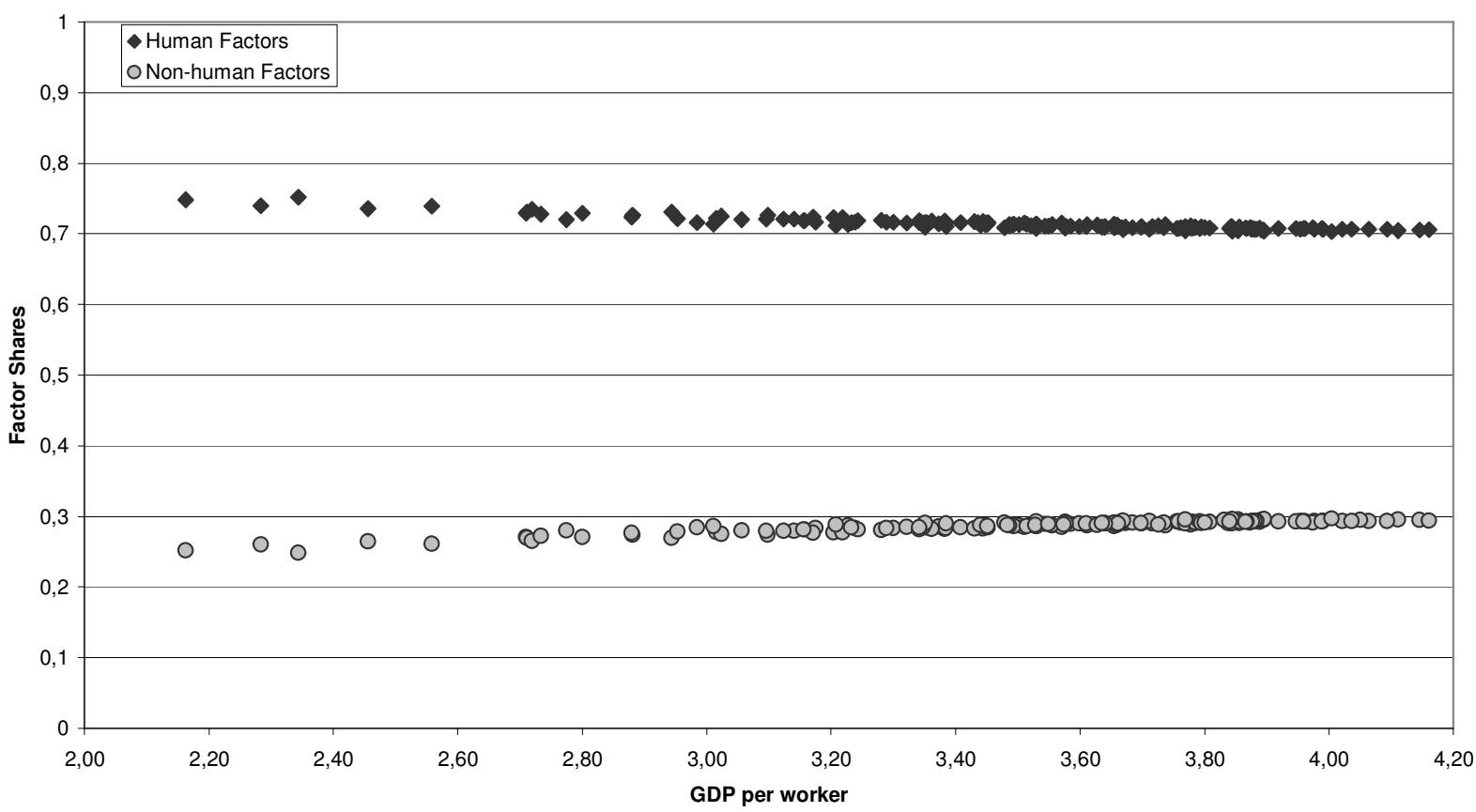

